\title{
Competição de cultivares de alface sob cultivo hidropônico 'NFT' em três diferentes espaçamentos.
}

\author{
Ronan Gualberto ${ }^{1}$; Francisco Vilela Resende'; Leila Trevizan Braz ${ }^{\mathbf{1}}$. \\ ${ }^{1}$ UNIMAR - FCA, C. Postal 554, 17.525-902 Marília - SP; ${ }^{2}$ UNESP - FCAV, Dep ${ }^{\text {to. }}$ de Horticultura, Jaboticabal - SP.
}

\section{RESUMO}

Com o objetivo de avaliar o desempenho de seis cultivares de alface do tipo lisa (Babá de Verão, Brasil 303, Elisa, Karla, Lívia e Monalisa) em três espaçamentos $(25 \times 20,25 \times 25$ e $25 \times 30 \mathrm{~cm})$, cultivadas em sistema hidropônico 'NFT', realizou-se um experimento na Fazenda Experimental da Universidade de Marília (SP), no período de 23 de setembro a 21 de novembro de 1997. Foram avaliadas as características comprimento de caule, produção de matéria fresca por planta e por área e produção de matéria seca da parte aérea, da raiz e total. O delineamento experimental adotado foi o de blocos casualizados, em esquema fatorial $6 \times 3$, com três repetições. Não houve efeito significativo da interação entre cultivares e espaçamentos. As cultivares Babá de Verão, Lívia e Elisa se destacaram pela produção de matéria fresca e matéria seca total. As cultivares Monalisa e Karla mostraram-se menos suscetíveis ao pendoamento precoce, enquanto a 'Babá de Verão' foi a mais suscetível. Não foi verificada influência significativa dos espaçamentos sobre as características estudadas, exceto para a produção por área, onde independente das cultivares utilizadas, o espaçamento $25 \times 20$ propiciou uma produção de $4,465 \mathrm{Kg} / \mathrm{m}^{2}$, superior aos demais espaçamentos utilizados. Assim. Produções significativamente inferiores foram obtidas nos tratamentos 25 x $25 \mathrm{~cm}$ e $25 \times 30 \mathrm{~cm}: 3,583$ e $3,304 \mathrm{Kg} / \mathrm{m}^{2}$, respectivamente, devido à redução no número de plantas por $\mathrm{m}^{2}$.

Palavras-chave: Lactuca sativa, técnica de cultivo, hidroponia, alface lisa.

\section{ABSTRACT}

Butterhead lettuce cultivars under 'NFT' hydroponic cultivation in three different spacings.

An experiment was carried out at the Experimental Farm, of Marília University, from September 23th 1997 to November 21st 1997 with the objective of evaluating the performance of six butterhead lettuce cultivars (Babá de Verão, Brasil 303, Elisa, Karla, Lívia and Monalisa) in three spacings ( 25 × 20, 25 x 25 and 25 x 30 $\mathrm{cm}$ ), cultivated under a hydroponic system 'NFT'. Stem length, fresh matter yield per plant and per area, and aerial part and root dry matter weight were evaluated. The Experiment was laid out as a $6 \times 3$ factorial randomised block design with three replications per treatment. No considerable effect on yield was found in the interaction between cultivars and spacing. Cultivars Babá de Verão, Lívia and Elisa stood out in terms of total fresh and dry matter weight. Cultivars Monalisa and Karla showed less susceptibility to bolting, and 'Babá de Verão' the greatest susceptibility. Spacing did not have any significant influence on the characteristics studied, with the exception of yield per area. Independent of cultivar, the highest marketable yield $\left(4.465 \mathrm{Kg} / \mathrm{m}^{2}\right)$ was obtained with the spacing $25 \times 20 \mathrm{~cm}$, with significantly lower yields measured in the $25 \times 25 \mathrm{~cm}$ and $25 \times 30$ cm treatments: 3.583 and $3.304 \mathrm{Kg} / \mathrm{m}^{2}$, respectively, due to a reduction in the number of plants per square meter.

Keywords: Lactuca sativa , culture technique, hydroponic, butterhead lettuce.

\section{(Aceito para publicação em 16 de abril de 1999)}

$\mathrm{S}$ endo produto perecível e consumido in natura, a preocupação com a qualidade da alface, seja nutricional, ou sanitária, deve ser mantida em todos os seguimentos envolvidos no processo da produção e comercialização (Rezende, 1991). Neste contexto, os cultivos hidropônicos representam uma alternativa à cultura convencional, por possibilitarem a obtenção de produtos de qualidade superior, mais uniformes, com maior produtividade, menor custo de mão-de-obra, menor gasto de água e de insumos agrícolas e preservação do meio ambiente (Jensen \& Collins, 1983; Castelane \& Araújo, 1994; Faquin et al., 1996; Resh, 1997; Garcia et al., 1998).

No Brasil, os cultivos hidropônicos são recentes, mas já podem ser encontrados nos cinturões verdes de algumas capitais, e também em algumas cidades do interior. A alface é a espécie mais difundida entre os produtores hidropônicos, provavelmente devido ao seu pioneirismo como cultura hidropônica no país, bem como, por se tratar de cultura de manejo mais fácil e principalmente por ser de ciclo curto (45 - 60 dias) garantindo assim retorno de capital mais rápido. A maior fração dos cultivos hidropônicos de alface, no país, é feita pela técnica do fluxo laminar de nutrientes $(\mathrm{NFT}=$ Nutrient Film Tecnique). Os primeiros produtores brasileiros instalaram essa técnica a partir de informações geradas por pesquisas executadas na Europa, Estados Unidos e Austrália, onde as condições de clima, custos de produção e mercado diferem muito das locais. Isso proporcionou muitas vezes resultados diferentes dos esperados. Frente a essa situa- ção, alguns produtores desistiram do cultivo, outros criaram e adaptaram suas próprias tecnologias, baseando-se em tentativas e na troca de experiências (Koefender, 1996).

Atualmente no Brasil, já existem informações científicas a respeito de alface em 'NFT', as quais foram desenvolvidas em estações experimentais, centros de pesquisa e universidades. No entanto, essas informações ainda não são suficientes e, é necessário que mais pesquisas sejam realizadas para compreender melhor essa técnica, nas condições locais e para essa cultura, para assim, poder resolver os problemas que os produtores possam vir a ter, permitindo o avanço dessa área de produção agrícola e do conhecimento científico (Koefender, 1996; Bernardes, 1997; Cohen, 1998). 
Tabela 1. Comprimento de caule, matéria seca da parte aérea (MSPA), matéria seca de raiz (MSR), matéria seca total (MST), produção de matéria fresca por planta $(\mathrm{MF} / \mathrm{Pl})$ e por $\mathrm{m}^{2}\left(\mathrm{MF} / \mathrm{m}^{2}\right)$ de seis cultivares de alface em três espaçamentos no sistema hidropônico 'NFT'. Marília, UNIMAR, 1997.

\begin{tabular}{lccccccc}
\hline \multicolumn{1}{c}{ Cultivares } & $\begin{array}{c}\text { Compr. de } \\
\text { caule }(\mathbf{c m})\end{array}$ & MSP A (g) & MS R (g) & M ST (g) & MF/PI (g) & MF/m² $(\mathbf{K g})$ \\
\hline Monalisa & $7,31 \mathrm{~d}$ & $9,82 \mathrm{ab}$ & 2,33 & $12,37 \mathrm{ab}$ & $196,76 \mathrm{~b}$ & $3,204 \mathrm{~b}$ \\
Karla & $7,67 \mathrm{~d}$ & $8,86 \mathrm{~b}$ & 2,43 & $11,29 \mathrm{~b}$ & $235,82 \mathrm{ab}$ & $3,875 \mathrm{ab}$ \\
Lívia & $8,36 \mathrm{~cd}$ & $11,40 \mathrm{a}$ & 2,83 & $14,23 \mathrm{a}$ & $249,47 \mathrm{a}$ & $4,124 \mathrm{a}$ \\
Elisa & $9,56 \mathrm{bc}$ & $10,50 \mathrm{ab}$ & 2,70 & $13,20 \mathrm{ab}$ & $243,39 \mathrm{a}$ & $3,964 \mathrm{a}$ \\
Brasil-303 & $10,44 \mathrm{ab}$ & $8,63 \mathrm{~b}$ & 2,51 & $11,14 \mathrm{~b}$ & $211,69 \mathrm{ab}$ & $3,429 \mathrm{ab}$ \\
Babá de Verão & $12,06 \mathrm{a}$ & $11,40 \mathrm{a}$ & 2,66 & $14,06 \mathrm{a}$ & $252,75 \mathrm{a}$ & $4,108 \mathrm{a}$ \\
\hline Espaçamentos & & & & & & \\
\hline E1 $(25 \times 30 \mathrm{~cm})$ & 9,82 & 10,41 & 2,47 & 12,89 & 247,79 & $3,304 \mathrm{~b}$ \\
E2 $(25 \times 25 \mathrm{~cm})$ & 9,22 & 9,46 & 2,66 & 12,11 & 223,93 & $3,583 \mathrm{~b}$ \\
E3 $(25 \times 20 \mathrm{~cm})$ & 8,65 & 10,43 & 2,71 & 13,15 & 223,22 & $4,465 \mathrm{a}$ \\
\hline C.V. $(\%)$ & 19,35 & 19,43 & 20,45 & 19,21 & 18,52 & 17,70 \\
\hline
\end{tabular}

${ }^{1}$ Médias seguidas de mesma letra nas colunas não diferem entre si a 5\% de probabilidade, pelo Teste de Duncan.

Existem disponíveis no mercado muitas cultivares de alface, mas pouco se sabe a respeito da adaptação das mesmas ao sistema 'NFT'. Por enquanto, no Brasil, não ocorre a produção de sementes especificamente para o cultivo sem solo. Em 1990, as cultivares que se adaptaram ao meio hidropônico (em NFT) foram Brisa (tipo crespa) e Regina (tipo lisa); a partir de 1994 a cultivar Verônica (tipo crespa) e a cultivar Elisa (tipo lisa) têm se mostrado bastante adaptáveis ao sistema de hidroponia (Bernardes, 1997). Além disso, sabe-se também que o espaçamento entre plantas exerce uma grande influência no comportamento das mesmas, afetando-lhes, a arquitetura, o desenvolvimento, o peso, a qualidade e entre muitas outras características, a mais importante, a produção (Mondin, 1988). No sistema hidropônico existem poucos trabalhos relacionados ao assunto. Para variedades européias tem-se observado espaçamentos variando entre 17 e $19 \mathrm{~cm}$ dentro das linhas por 20 e $22 \mathrm{~cm}$ entre canais, no sistema 'NFT' (Abou-Hadid et al., 1996, Resh, 1997). Para cultivares tipo americana o espaçamento utilizado está em torno de $25 \times 25 \mathrm{~cm}$ (Resh, 1997). No Brasil os espaçamentos para as alfaces dos tipos lisa e crespa têm variado de 18 a $25 \mathrm{~cm}$ dentro das linhas por 20 a $30 \mathrm{~cm}$ entre as linhas, para o sistema hidropônico (Bernardes, 1996;
Faquin et al., 1996; Furlani, 1997a, b). Porém, não existe recomendação precisa de espaçamento para cada cultivar, pois as respostas de diferentes cultivares a diferentes espaçamentos não são concordantes.

Este estudo teve o objetivo de avaliar o desempenho de seis cultivares de alface lisa, em três espaçamentos, em cultivo hidropônico 'NFT'.

\section{MATERIAL E MÉTODOS}

O Experimento foi conduzido sob casa-de-vegetação na Fazenda Experimental da Universidade de Marília - SP, com altitude de $610 \mathrm{~m}$, latitude $22^{\circ} 12^{\prime}$ $50^{\prime \prime} \mathrm{S}$ e longitude $49^{\circ} 56^{\prime} 45^{\prime \prime} \mathrm{W}$, no período de 23 de setembro a 21 de novembro de 1997. A estufa utilizada foi do tipo túnel alto, com 4,0 $\mathrm{m}$ de pé direito, cobertura plástica de 150 micras de espessura e laterais protegidas com telas de polipropileno preto com $70 \%$ de sombreamento. Foram utilizadas seis cultivares de alface do grupo manteiga (folha lisa): Babá de Verão, Brasil-303, Elisa, Karla, Lívia e Monalisa, e três espaçamentos: $25 \times 20 \mathrm{~cm}, 25 \times 25 \mathrm{~cm}$ e 25 x $30 \mathrm{~cm}$.

O delineamento experimental adotado foi o de blocos casualizados, com três repetições, em esquema fatorial $6 \mathrm{x}$ 3. Foi utilizada a técnica do fluxo laminar de nutrientes $(\mathrm{NFT}=$ Nutrient
Film Technique ), que consiste em manter $2 / 3$ do sistema radicular imerso num filme de solução nutritiva mantido através de fluxo intermitente, obtido com o uso de um "Timer" mecânico, que acionava e desligava a moto bomba a intervalos de tempo pré determinados, em função das fases de cultivo. $\mathrm{O}$ experimento constituiu-se de três fases distintas: berçário, pré-crescimento e crescimento final. Os materiais foram semeados em bandejas de poliestireno expandido, com 288 células, em vermiculita. Após a emergência (4 dias após semeadura) as bandejas foram colocadas nas piscinas (berçário) com a solução nutritiva recirculando durante o dia, sendo que no período noturno a moto bomba permanecia desligada. Nesta fase a condutividade elétrica foi mantida entre 1,0 e $1,5 \mathrm{mS} \mathrm{cm}^{-1}$ Após 20 dias da semeadura as mudas foram retiradas das bandejas e as raízes lavadas para retirada da vermiculita, após o qual foram transplantadas para as bancadas de précrescimento. Nessas bancadas, em telhas de fibrocimento cobertas por placas de isopor perfuradas, com células espaçadas de 7,5 x $5,0 \mathrm{~cm}$ e diâmetro de $3,0 \mathrm{~cm}$, as plantas permaneceram durante 15 dias. Neste ponto, as plantas foram transplantadas para a fase final.

$\mathrm{Na}$ fase de crescimento final as bancadas com 12,0 m de comprimento, $2,0 \mathrm{~m}$ de largura e $2 \%$ de declividade 
eram de tubos de PVC (75 mm) perfurados, com diâmetro de $5,0 \mathrm{~cm}$ e espaçados a cada $25 \mathrm{~cm}$. Nesta fase os espaçamentos foram definidos, sendo que nas três bancadas os tubos foram espaçados de 20, 25 e $30 \mathrm{~cm}$, correspondendo a 10, 8 e 7 tubos, respectivamente, por bancada. $\mathrm{O}$ número total de plantas por parcela variou em função do número de tubos de PVC por bancada. Na parcela útil foram avaliadas 4 plantas, em todos os três espaçamentos.

As plantas permaneceram nesta fase 24 dias, não ocorrendo diferenças marcantes no ciclo das cultivares testadas, onde então foram realizadas a colheita e as avaliações das características: comprimento de caule, produção de matéria fresca por planta e por área e, produção de matéria seca da parte aérea, de raiz e total.

A solução nutritiva utilizada em todo o ciclo da cultura foi a recomendada por, (Basso \& Bernardes, 1993), utilizandose por litro: $236,3 \mathrm{mg}$ de N, 39,0 $\mathrm{mg}$ de P, 224,9 mg de K, 228,0 mg de Ca, 33,7 $\mathrm{mg}$ de $\mathrm{Mg}$, 46,3 mg de S, 0,24 mg de B, 0,02 mg de $\mathrm{Cu}, 5,0 \mathrm{mg}$ de $\mathrm{Fe}, 0,23 \mathrm{mg}$ de Mn, 0,03 mg de Mo e 0,05 mg de Zn. No caso do Ferro, foi utilizado $40 \mathrm{~g}$ por 1.000 litros de solução de ferro EDDHA - Ferrilene.

Tanto na fase de pré crescimento como na de crescimento final, diariamente foi feita a reposição do volume absorvido e evapotranspirado de solução nutritiva pelas plantas, em função da condutividade elétrica, sendo que, quando através de um condutivímetro, observou-se valores abaixo de $1,7 \mathrm{mS}$ $\mathrm{cm}^{-1}$ era acrescentada solução e quando os valores eram superiores a $2,0 \mathrm{mS} \mathrm{cm}$ ${ }^{1}$ adicionava-se água. Esses valores foram definidos em função da época de realização do experimento (Furlani, 1995). Em relação ao pH da solução, este foi monitorado diariamente para verificar se estava na faixa de 5,5 a 6,5. Como a cada 15 dias era renovada toda a solução do tanque de bombeamento, não houve necessidade de ajuste. A água utilizada era de poço semi artesiano, a qual tinha valor de $\mathrm{pH}$ de 6,8 e condutividade elétrica de $0,0 \mathrm{mS} \mathrm{cm}^{-1}$.
O sistema de bombeamento da solução nutritiva do reservatório para as fases de pré-crescimento e final era acionado por meio de um timer, que iniciava a circulação da solução às 7:00 horas, sendo o bombeamento intermitente, circulando-se a solução a intervalos de 10 minutos por períodos de $20 \mathrm{mi}$ nutos até às 19 horas. Durante a noite, o timer acionava apenas duas vezes, funcionado durante 20 minutos cada vez, às 23:00 e 3:00 horas. No período diurno, das 9:00 às 17:00 horas, o interior da casa-de-vegetação era nebulizada por 40 segundos, a cada 5 minutos, visando minimizar o efeito das altas temperaturas no interior da mesma. Foi feito o acompanhamento da temperatura da solução nutritiva no reservatório, sendo que a mesma não chegou ao limite extremo de $30^{\circ} \mathrm{C}$ (Faquin et al, 1996).

Os dados foram submetidos à análise de variância e as médias comparadas pelo teste de Duncan a 5\% de probabilidade.

\section{RESULTADOS E DISCUSSÃO}

Observou-se pelo resumo da análise de variância que ocorreram diferenças significativas entre cultivares para todos os caracteres avaliados, com exceção de matéria seca de raiz. Diferença estatística significativa entre espaçamentos foi observada para produção de matéria fresca por área. A interação cultivar x espaçamento não foi significativa para nenhum dos caracteres avaliados (Tabela 1).

Para o comprimento de caule (Tabela 1), constatou-se que as cultivares Monalisa, Karla e Lívia, foram as menos afetadas pela temperatura, que é o agente externo responsável pelo pendoamento precoce na alface.

Nos caracteres matéria seca da parte aérea e matéria seca total se destacaram as cultivares Lívia e Babá de Verão, seguidas por 'Elisa' e 'Monalisa'. Quanto à matéria seca de raiz, todas as cultivares apresentaram valores semelhantes (Tabela 1).

Em relação ao peso de matéria fresca da planta inteira, se destacaram as cultivares Babá de Verão, Lívia e Elisa
$(252,75 ; 249,47$ e $243,39 \mathrm{~g}$, respectivamente), o mesmo acontecendo para o peso de matéria fresca/m² $(4,11 ; 4,12$ e 3,96 Kg, respectivamente). Deve se ressaltar que a 'Babá de Verão', apesar de apresentar alta produção, sua qualidade foi afetada em função do pendoamento precoce. O peso médio da parte aérea apresentado pela cultivar Elisa (243,3 g) foi menor do que o obtido por Cortez et al. (1998). Entretanto este valor foi maior do que os obtidos por Delistoianov (1997) e Vaz \& Junqueira (1998). Os valores apresentados pelas cultivares Babá de Verão e Brasil-303 para a mesma característica foram maiores do que os obtidos por Delistoianov (1997).

Em relação aos espaçamentos, para a produção de matéria fresca $/ \mathrm{m}^{2}$ o espaçamento mais reduzido $(25 \times 20 \mathrm{~cm})$ mostrou uma produção superior aos demais, independente da cultivar utilizada. Estes resultados estão de acordo com os observados em solo por Maciel (1968) e Mondin (1988). Como a comercialização da alface é feita por cabeça ou pé, este espaçamento seria o ideal, uma vez que ele propicia uma produtividade de 20 pés/ $\mathrm{m}^{2}$, contra 16 do espaçamento intermediário e 13 do maior.

Conclui-se que, em cultivo hidropônico, sistema NFT, as cultivares Lívia e Elisa se destacaram tanto em produção quanto em qualidade, e que o espaçamento mais indicado é o de 25 x $20 \mathrm{~cm}$.

\section{LITERATURA CITADA}

ABOU-HADID, A.F.; ABD-ELMONIEM, E.M.; EL-SHINAWY, M.Z; ABOU-ELSOUD, M. Composition of lettuce plants in hydroponic sistem. In: ABOU-HADID, A.F.; JONES, R.A. Procedings of the International Symposium on strategies for market oriented greenhouse production. Acta Horticulturae, v. 434, p. 59-66, 1996.

BASSO, E.N.; BERNARDES, L.J.L. Hidroponia: técnicas de implantação comercial do cultivo de alface. Piracicaba, 1993. 49 p. (Apostila).

BERNARDES, L.J.L. Hidroponia da alface: uma história de sucesso. Piracicaba: Estação Experimental de Hidroponia "Alface \& Cia", 1997. $129 \mathrm{p}$.

BERNARDES, L.J.L. O espaçamento de crescimento da alface. Piracicaba, Hidropomanias \& Cia., n. 2, p. 5, abr. 1996. 
CASTELlANE, P.D.; ARAÚJO, J.A.C. Cultivo sem solo - hidroponia. Jaboticabal: FUNEP/ UNESP, 1994. 43 p.

COHEN, A.I. Análise do comportamento da alface em sistema hidropônico tipo NFT, com e sem o uso de nutrientes quelatizados na solução nutritiva. Jaboticabal: FCAV - UNESP, 1998, 91 p. (Tese mestrado)

CORTEZ, G.E.P.; ARAÚJO, J.A.C.; BELLIGIERI, P.A. Cultivo hidropônico de alface com o aproveitamento de resíduos da criação intensiva de peixes. In: CONGRESSO BRASILEIRO DE OLERICULTURA, 38., 1998, Petrolina. Resumos... Petrolina: SOB, 1998.

DELISTOIANOV, F. Produção, teores de nitrato e capacidade de rebrota de cultivares de alfa$c e$, sob estufa, em hidroponia e solo, no verão e outono. Viçosa: UFV, 1997, 76 p. (Tese mestrado).

FAQUIN, V.; FURTINI NETO, A.E.; VILELA, L.A.A. Produção de alface em hidroponia. Lavras: UFLA/FAEPE, 1996. 50 p. (Apostila).
FURLANI, P.R. Cultivo de alface pela técnica de hidroponia NFT. Campinas, Instituto agronômico, 1995. 18 p. (documentos IAC, 55).

FURLANI, P.R. El sistema NFT: producción de plantas de hoja. In: CONFERENCIA INTERNACIONAL DE HIDROPONIA COMERCIAL, Lima: UNALM, 1997a. p. 59 - 65.

FURLANI, P.R. Instruções para o cultivo de hortaliças de folhas pela técnica de hidroponiaNFT. Campinas: IAC, 1997b. 30 p. (Boletim técnico, 168).

JENSEN, M.H.; COLLINS, W.L. Hidroponic vegetable production. Horticultural of Plant Nutrition, v. 5, p. 483 - 558, 1983.

KOEFENDER, V.N. Crescimento e absorção de nutrientes pela alface cultivada em fluxo laminar de solução. Piracicaba: ESALQ, 1996, 85 p. (Tese mestrado).

MACIEL, R.F.P. Estudo sobre a influência do espaçamento, níveis de irrigação e adubação na cultura da alface (Lactuca sativa L.). Viçosa: UFV, 1968, 76 p. (Tese mestrado).
MONDIN, M. Influência de espaçamentos, métodos de plantio e de sementes nuas e peletizadas, na produção de duas cultivares de alface (Lactuca sativa $L$.). Lavras: UFLA, 1988, 59 p. (Tese mestrado).

REZENDE, A.C. Controle da qualidade de hortaliças comercializadas nas centrais de abastecimento. In: SEMINÁRIO INTERNACIONAL SOBRE QUALIDADE DE HORTALIÇAS E FRUTAS FRESCAS. Anais... Brasília: EMBRAPA - CNPH, 1991. p. 20 - 26.

VAZ, R.M.R.; JUNQUEIRA, A.M.R. Desempehno de três cultivares de alface sob cultivo hidropônico. Horticultura Brasileira, Brasília, v. 16, n. 2, p. 178 - 189, nov. 1998.

RESH, H.M. Cultivos hidroponicos: nuevas técnicas de producción. 4 ed. Madrid: MundiPrensa, 1997. 378 p. 